\title{
Development of Ceramic Three-Dimensional Design System Based on Sketch
}

\author{
Li Busheng* and Hu Jingfang
}

School of Information Engineering, Jingdezhen Ceramic Institute, Jiangxi, 333403, P.R. China

\begin{abstract}
The paper has analyzed and digested the related literatures from home and aboard, summarized techniques and theoretical methods of the relevant prototype systems. Based on the understanding of the present situation of the domestic and foreign sketches technology application basis, through the existing ceramics product design process and production process flow of the detailed ceramic products of design process are in-depth analysis and decomposition is proposed based on the sketch of the computer aided design ceramic technology, and on the basis of the development of the corresponding ceramic design software.
\end{abstract}

Keywords: Freehand sketching, three- dimensional, ceramic design, CAD, ceramic products.

\section{INTRODUCTION}

The sketch is a special form of the symbol system which has the characteristics of semantics, syntax and fuzzy $[1,2]$. And could satisfy the lengthways and lateral conceptual work of the designers. Designers can define the approximate contour shape of the graphic (Topology to the sketches form of expression), transform the hand-draw graphic into geometry figure, convert line type, line width and other information into attributive character, and define a specific graphics object by hand drawing the sketch.

On the internationally there a lot of studies available on sketch technology, and have developed many prototype systems. For example, DENIM and SketchySPICE are the two application examples which based on the SATIN free handwriting Application development kit, developed by the UCBerkeley University [3]. DENIM is a web design tools, and it supports the information processing on the concept devise stage, allows the designer to sketch the web quickly, and has the gestures design and stroke treatment; SketchySPICE is a simple circuit design tools, users can sketch and it has connection with the gate circuit, which joined the identification of specific features and domain knowledge. But these systems mostly concentrate on expression of the design result and don't have enough ancillary support on shape design process at present. The research of sketch technology in our country mainly rests on the exploratory stage, although there are many kinds of softwares about ceramic product design present locally and abroad, but sketch technology's use in this field is still a blank space. The intelligent sketch technology on ceramic product design is referred in this text to try to combine the superiority of unarmed rough softwares with the superiority

*Address correspondence to this author at the School of Information Engineering, Jingdezhen Ceramic Institute, Jiangxi, 333403, P.R. China; Tel: 13879811027; E-mail: abulbs@163.com of CAD technology to offer an intelligent sketch platform, and set up a bridge between the paper sketch and design technology supported by computer.

\section{SKETCH DESIGN TECHNOLOGY RESEARCH STATUS AND DEVELOPMENT TREND}

Sketch design technology is a modeling technology that advanced with the development of solid modeling technology and satisfied the industry stylist's traditional hand painted custom, it covered the wide gap between the traditional CAD system and industry design effectively. The key point of this technology lies in three aspects: first of all, the human-computer interaction techniques in the design process, that is how could a design system imitate the hand painted design effectively [4]; secondly, the sketch recognition technology, it means which recognized method and recognized arithmetic should be taken to increase the recognition rate; thirdly, sketch reconstruction techniques, that is how to complete the 3D entity reconstruction by sketch technology [5]. And the research of human-computer interaction techniques mainly reflect on the human interface technology and virtual simulation technique and so on. With the development of hardware and software such as multimedia and virtual reality, human-computer interaction techniques have had a great change, natural user interface, fictitious interface, multi-user interface, multichannel interface and other research direction have appeared. The researches on recognition technology and sketch reconstruction aspect are also not few.

Sketch technology is the key point to pick up the design ideas of designers. The sketch system that supports free hand painting could accept the pen drive input point set pickup technology that is based on the timing-space relativity, and it could make a pretreatment to the temporal and spatial information, it will build a spatial graphic point-group with great timing-space relativity. Finally, the suitable recognition algorithm is used to get the graphic object. Graphic 
recognition is very importation in understanding the line chart, especially the engineering drawing. In recent years, we have left the table of identification on some graphics, such as character separation and identification, arrow recognition, circular arc recognition, dotted line recognition, label recognition and pane recognition. These kinds of graphic recognition ways are all private, could only be used for individual type pattern recognition, there is not a global way yet. It will produce a great result in recognizing some clean and simple drawing, but it is unsatisfactory in the middling complicate or more complicate drawing recognition.

Sketch rebuild technique is the key point in making a $3 \mathrm{D}$ modeling from designer's 2D and 3D design sketch, its development is relativity mature. There are some product concept shape fast generating systems and CAD system that based on the sketch. Some big CAD/CAM software systems could provide corresponding module.

Sketch design system as a CAD system in the expression and interaction [6,7], has a lot of inconvenience because of the interactive tools and technical limitations. Most CAD systems require users to provide more accurate information and steps to interact more cumbersomely, thus affecting the natural expression of design intention. In addition, it could not sustain the concept design very well and the seamless chaining between achieved and detailed design. Nowadays, sketch design is more and more accepted and used, because of the property it has it was an idealistic communication mode, and it could communicate in the different level of abstraction at the same time. There are more means and skills to support the human-computer communication, we can draw the sketch on the basis of different use or purpose, the introduction of the development of pen-based user interface and new interactive technology has provided an efficient and natural way of sketch design.

\section{CONCEPTUAL DESIGN OF HAND-PAINTED CERAMIC DESIGN SYSTEM}

Intelligent sketch technology is based on the study of design thinking, sketches behavior, its characteristics, the paper Sketch design technology and computer support each of which has its own strengths and weaknesses [8]. It will be a very meaningful work to combine their advantages together. Especially now the CAD technology which orients the detailed design stage has developed perfectly. It can guarantee the support and assistance of the computer for the entire design process, consistently unifying the entire design process. Moreover, the outstanding characteristics of the computer itself arebound to raise the level of efficiency and design at the early design stage, especially it can enhance the sketch design innovation performance through smart innovation and technology. The key to intelligent sketch technology is in-depth understanding of the draft plan to the behavior. Sketching behavior and design thinking are closely related. The sketches capture inherent human the behavior thinking outside or concrete which is a necessary extension of the visual image of the designers perception. Intelligent sketch technology for computer support, according to the characteristics of the computer itself can be roughly four to consider: Natural interaction behavior smart sketch; Sketch of expression and freedom of freehand sketch input; Design intent capture and sketch recognition; and sketch-based geometric modeling. Fig. (1) shows the computer support hand-painted ceramic pattern sketches technology framework.

\section{SYSTEM ANALYSIS OF CERAMIC DESIGN SYSTEM}

Ceramic design system's overall goal is to conform to the requirements of the ceramic product design and production process of digital design and manufacturing software system [9]. Research project can be subdivided into two major objectives, one is the realization of digital three-dimensional modeling of ceramic products; two is to realize the threedimensional model into numerical control machine tool $\mathrm{NC}$ code automatically. The content of the research and development mainly are five:

\subsection{Based on Design Process and Production Process of Product Components Decomposition}

The current ceramic enterprises in ceramic product design process and production process of detailed study, the design process of ceramic products for further analysis and decomposition, Exploring the project design of ceramic

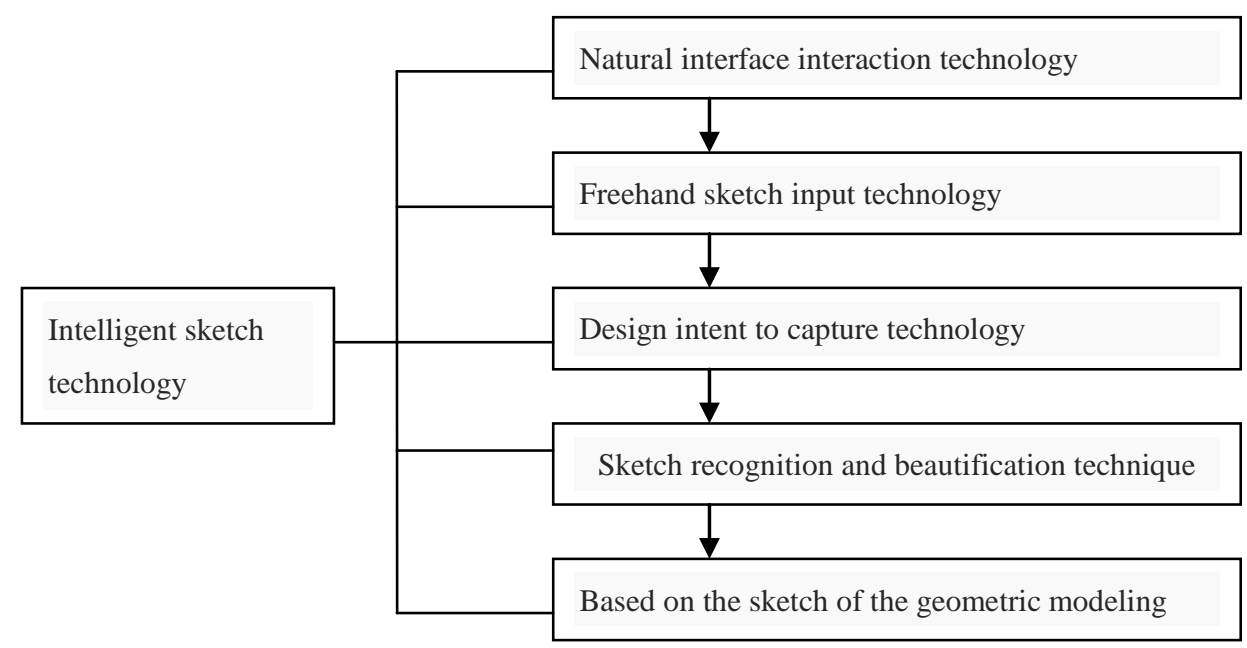

Fig. (1). Computer support of hand-painted ceramic pattern sketches technology framework. 
needs human interaction steps in the $3 \mathrm{~d}$ CAD system, and needs to be done by the system automatically in order to better improve enterprise's key steps in the efficiency of product design and in the decomposition on the basis of the design process to classify modeling of ceramic products, and finished components decomposition of complex products. Ceramic products decomposition is different from the mechanical parts and components industry and other industry products, ceramic products decomposition lies mainly in the design of the components in the process of decomposition, and the final product in general is not an integral whole, for example, in the design process for more complex products such as "pot" will be broken down parts into the pot body, the pot, a spout, the lid and lid knob, a girder of the pot, an ear piece [10]. And set up all kinds of parts in the three-dimensional model of the material library.

\subsection{Based on Parts of Ceramic Product Design Process Model Material}

After introducing products of components material library, ceramic product design steps and design process will bring revolutionary changes to existing enterprises. And redesigning of the product design process will guide the follow-up research process, to help us complete supervised and unsupervised design steps of the selection and implementation.

\subsection{Based on GSM Technology for Process Design of Ceramic Product Modeling Capabilities}

GSM technology Think3 company is a three-dimensional model of the world's top global modeling technology, the technology can be achieved by simple operating mode for the completion of existing 3D model for deformation and transform functions, especially good than the existing models for different transformation and global changes, since personalized ceramic product design provides a fast design method. The function in the ceramic product 3D CAD system of ceramic product CAD system is introduced due degree of ease of use and creative design brings revolutionary change.

\subsection{Based on ThinkCore Ceramic 3D CAD System}

Application think3 ThinkCore development platform provided by the company, according to the previous analysis and the result of the design development is suitable for ceramic industry ceramic product three-dimensional CAD system, in addition to the system, the design of the new process quickly with the three-dimensional modeling process of ceramic products, also has application in the ceramic industry since it has features, such as: supports accurate map function, you can manually drag on ceramic surface map location and size of support in an entity or curved surface can post more picture design, design to adapt to the curved surface; Supports material expansion, the realistic play dyeing effect, the ceramic products of simulation material and decorative effect, and so on.
4.5. Ceramic Three-Dimensional Digital Model into the Cutter Location File Automatic Transformation System

Using CNC machine processing and three-dimensional digital model, the three-dimensional digital model needs to be placed into cutter location file, then convert the file into a numerical control machine ceramic sculpture of the NC code, in this way automatic processing can be done. This process needs to be done by a professional computer technician. We will simplify the process of a series of research and development of automatic transformation system, the realization of common operators for simple settings can complete three-dimensional digital model to the transformation of the cutter location file.

\section{THE CERAMIC DESIGN SYSTEM FUNCTIONAL DESIGN AND THE BASIC IDEA}

In the early stages of the ceramic product design, the designer's requirements are often vague, the design may just remain in style with a brief description. Designers are generally based on their own experience, or according to the requirements of customers, from the case library to extract one or several programs, and then complete the selection and modification of the design with the clients. In this case, there is conflict between the designers of the program and the users are not satisfied with the existing program or part of the program, and also want their full participation in the scheme comments. Faced with these requirements of the customers in the design process, designers want to able to give quick feedback, timely conversion needs quick practicable sketch program, and modification in real time based on customer feedback.

In response to these needs, we propose a computer-aided sketch to get the designer's intent, to achieve the process of design. So-called sketch outlining preliminary program, is an interactive interface which lets designers to express design, pays more attention to the representation of the design concept, and for the size does not require a high level of accuracy. In the initial stages of the design, the designers often use of simple lines quickly forming lay outs the eyes of a rough sketch program. Simple sketch painting on the one hand, real-time recording of inspiration for designers, but also to provide quick service to customers with more design, benefiting the designers instead of spending a lot of time and effort and not satisfying the customers. Then sketch plays a role of a bridge between designers and customers.

Most of the designers now have adapted the twodimensional sketch design, graphic design, after all, not the design of the final results, customers want to see the ceramic design three-dimensional effect figure. The key design features of the system for the three-dimensional effect is that once the two-dimensional sketch program was recognized by the designers and customers, and how to convert. Designers have accumulated a lot of experience and success stories, and often complete the new program by take design image and modifying it (Including the experience of other 
designers). So at this time the focus of the design is the choice of what type of style ceramic parts layout and how the pattern is design. In order to meet the designer's design habits, ceramic products are broken down into daily ceramics, sanitary ceramics and architectural ceramics and other categories, and the components of the threedimensional model disaggregated into input Gallery.

\section{THE REALIZATION OF CERAMIC DESIGN SYSTEM}

Sketch-based computer-aided ceramic design system used $\mathrm{VC}++6.0$ as the development tools, and used the ThinkDesign different categories to build 3D model library, including porcelain and ceramics, building ceramics and sanitary ceramics material library. Ceramic product design process through a detailed study of the design process and production process of ceramic products ceramic enterprises, in-depth analysis and decomposition steps excavated ceramic three-dimensional CAD system requires human-computer interaction, and the need by the system automatically completes the key steps to better enhance the efficiency of enterprise design products; modeling of ceramic products is classified based on the decomposition of the design process, and breaking down the complex products to complete exploded. Breaking down of Ceramic products is different from the product parts of the machinery industry, and other industries, the breaking down of ceramic products, main parts in the design process, decomposition, and the final product under normal circumstances is an undivided whole. For example, in the design process, for more complex products in household ceramic products such as "pot", its components are broken down into the pot body, pot, spout, lid and lid knob, beam lifting the pot, there mention ear parts. Material library, then creates a three-dimensional model of the various components of the teapot material library of three-dimensional model shown in Fig. (2).

In the component material library after the introduction of the product, the design steps and design process of a ceramic product are bound to bring a revolutionary change to existing enterprise need not between different software systems model of the product back and tossed away cause details lost; redesign of the product design process will guide the subsequent course of the study, to help us complete supervision, selection and implementation of the design of semi-supervised and unsupervised steps. For example, to achieve a teapot design we can select the desired individual components in the material library, and then assemble them together to local tensile modeling through various components based on customer needs, setting parameters, and finally decoration.

The system relies on ThinkDesign's advanced technology surface manipulation, solid model, and kernel. And use top solid modeling technology GSM created by ThinkDesign to develop easy-to-use ceramic products profiled structure function. Establishing the 3D material library of classification of ceramic products component models to help product designers to quickly design a new product.

By this method may produce a plurality of threedimensional modeling program, this is because the 3D model of the component material library is a one-to-many mapping from the 2D map to ceramic products; while the combination of the different member is a many-to-many mapping. The demand is not very clear and they have doubts, therefore, in the design process, customers can not only express their views, can even experience the choice of participation in program design activities and it provides designers a number of options.

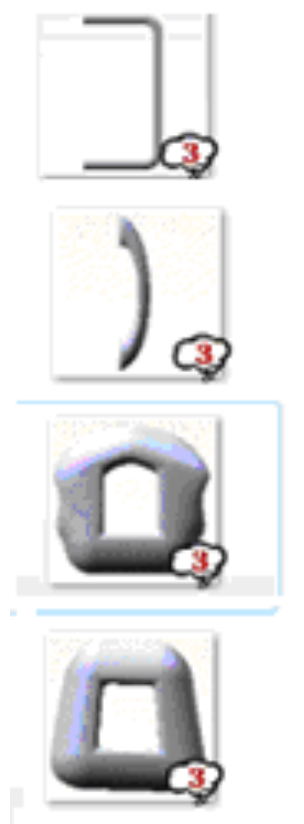

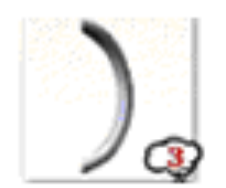
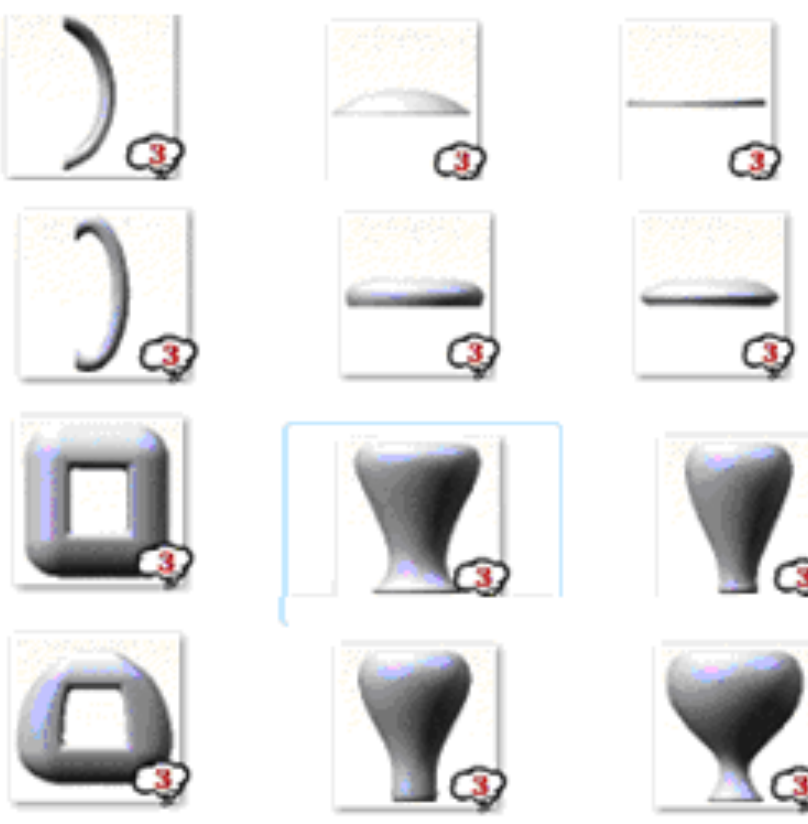
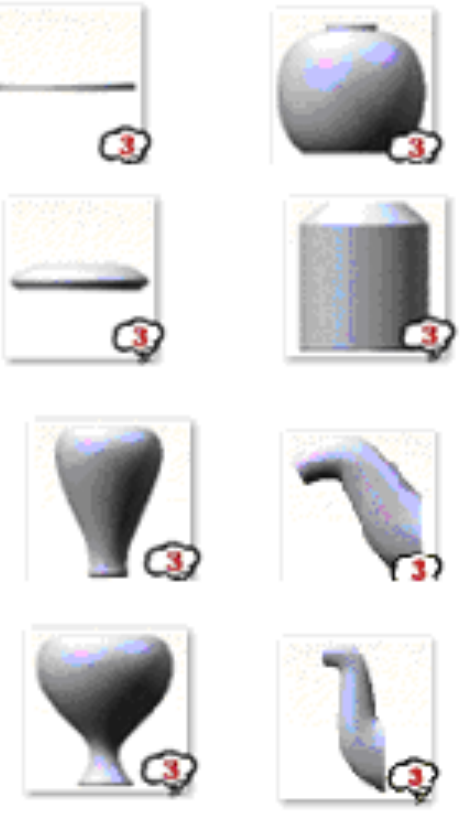
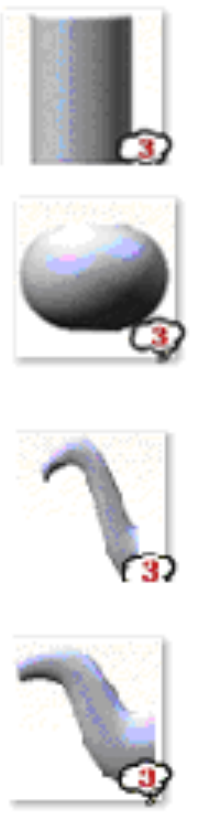

Fig. (2). The teapot three-dimensional model material library. 


\section{CONCLUSION}

Conceptual design sketch-based ceramic technology can help designers to take full advantage of existing experience and knowledge in the conceptual design stage, and make in a shorter time and quality design. At the same time, ceramic products, components taken from the three-dimensional model material library of the system can be combined with a large number of programs, and increase the choice of designers and users.

\section{CONFLICT OF INTEREST}

The author confirms that this article content has no conflict of interest.

\section{ACKNOWLEDGEMENTS}

Declared none.

\section{REFERENCES}

[1] E. Yi-luen Do, M.D. Gross, B. Neiman, and C. Zimring, "Intentions in and Relations Among Design Drawings", Design Studies, vol. 21, pp. 483-503, 2000.
[2] Jinke, "The usage of hand-painted performance in art design", Southwest Agricultural University (Social Science), vol. 4, pp. 6, 2006.

[3] F.G. Sheng, "Key technology research on the computeraided sketch design that oriented to the concept expression", Zhejiang University, 2007.

[4] C. Yan, "Discussion the importance of hand-drawn sketches of product designers", Science and Technology Information, vol. 6, 2009.

[5] F.Y. Gang, "Virtual ceramic design system supporting pen input", Computer Aided Design and Computer Graphics, vol. 14, pp. 877879, 2002.

[6] S.B. Hua, "The smart sketches Research for product conceptual design", XiAn, pp. 83-93, 2003.

[7] D. Zhan, "Hand-painted-based way to interact with threedimensional modeling", Zhejiang University, 2008.

[8] X. Hao, F.G. Zheng, W.M. Feng, L. Xin, S. G. Yu, "Shape from shading freehand sketches 3D modeling algorithm", Journal of Engineering Graphics, vol. 8, p. 30, 2006.

[9] S.-F. Qin, D.K. Wright, I.N. Jordanov, "From on- line sketching to 2D and 3D geometry: system based on fuzzy knowledge", Computer-Aided Design, vol. 32, pp. 855-866, 2000.

[10] T.F. Ansary, M. Daoudi, J.P. Vandeborre, “A Bayesian 3D search engine using adaptive views clustering, IEEE Transactions on Multimedia, vol. 9, pp. 78-88, 2007. 